\title{
Prática da compostagem em microescala como fator para valorização de resíduos sólidos orgânicos
}

A acelerada produção de resíduos sólidos urbanos e, principalmente resíduos orgânicos cria a necessidade de se buscar alternativas para reaproveitar e valorizar a matéria orgânica. A compostagem é um método de transformação da matéria orgânica em composto, que contribui para redução da disposição de resíduos em aterro sanitário, além de trazer benefícios econômicos e atender aos preceitos da Política Nacional de Resíduos Sólidos. O presente trabalho tem como principal objetivo avaliar o processo de compostagem em microescala. Neste trabalho foram montadas três pilhas de compostagem em microescala, utilizando resíduos orgânicos do preparo de refeições e materiais orgânicos provenientes de jardinagem. O processo de compostagem foi monitorado por um período de 90 dias. Após esse período, amostras do composto formado foram caracterizadas. Por meio do monitoramento do processo de compostagem e caracterização do composto, constatouse que os compostos produzidos apresentaram boa qualidade e, podem ser utilizados como substrato para enriquecimento de solo, demonstrando a viabilidade da compostagem em microescala.

Palavras-chave: Resíduos Sólidos Orgânicos; Matéria Orgânica; Compostagem; Microescala; Qualidade do Composto.

\section{Micro-composting practice as factor for the valuation of organic solid waste}

\begin{abstract}
The accelerated production of solid urban waste and, mainly, organic waste creates the need to find alternatives to reuse and value organic matter. Composting is a method of transforming organic matter into compost, which contributes to reducing waste disposal in landfills, as well as bringing economic benefits and meeting the requirements of the National Solid Waste Policy. The present work has as main objective to evaluate the composting process in microscale. In this work three compost heaps were assembled in microscale, using organic waste from the preparation of meals and organic materials from gardening. The composting process was monitored for a period of 90 days. After this time, samples of the formed compound were characterized. Through the monitoring of the composting process and the characterization of the compost, it was verified that the produced compounds presented good quality and can be used as substrate for soil enrichment, demonstrating the feasibility of composting in microscale.
\end{abstract}

Keywords: Organic Solid Waste; Organic Matter; Composting; Microscale; Compost Quality.

Topic: Notas Científicas

Reviewed anonymously in the process of blind peer.
Received: 25/07/2017

Approved: 25/10/2017
Nathália Silva de Souza

Faculdade Integrada Cantareira, Brasil http://lattes.cnpq.br/5395630864773804 nssousa24@gmail.com

\section{Giovano Candiani}

Universidade Federal do $A B C$, Brasil

http://lattes.cnpq.br/9950995765229751

giovanocandiani@gmail.com

\section{Referencing this:}

SOUZA, N. S.; CANDIANI, G.. Prática da compostagem em microescala como fator para valorização de resíduos sólidos orgânicos. Revista Ibero-Americana de Ciências Ambientais, v.8, n.4, p.327-335, 2017. DOI: http://doi.org/10.6008/SPC2179-6858.2017.004.0026 


\section{INTRODUÇÃO}

Compostagem é uma transformação de resíduos sólidos orgânicos (RSO), através de processos físicos, químicos e biológicos, que carecem de monitoramento, em um material mais estável, condicionador orgânico do solo (BARREIRA et al., 2006; CARLESSO et al., 2011; GOMES et al., 2015). O método é conhecido há séculos, e técnicas simplificadas e tradicionais ainda são utilizadas, em caráter domiciliar e artesanal. Em escalas maiores depende de alternativas tecnológicas (KIEHL, 2004; INÁCIO et al., 2009; PEREIRA NETO, 2013). Seu uso é muito recomendado, pois reduz a quantidade de matéria orgânica que precisaria ser disposta em aterro sanitário e aporta potencialmente aos solos e áreas verdes um insumo condicionador nutricional (LIMA, 2004; LOUREIRO et al., 2007; MATOS, 2014; SIQUEIRA et al., 2015).

A matéria orgânica é transformada em etapas, como resultado da ação das atividades microbiológicas, que se caracterizam em: biodigestão (fase em que a matéria orgânica se bioestabiliza) e maturação (etapa que ocorre a humificação da matéria orgânica, resultando em um produto final, denominado húmus ou composto). O período de compostagem depende fundamentalmente do processo utilizado e do material orgânico a ser compostado, em geral este período gira em torno de 1 a 6 meses, porém normalmente em escalas pequenas, 3 meses é suficiente para o término do processo (BRITO, 2008; INÁCIO et al., 2009; BARROS, 2012; PEREIRA NETO, 2013; SIQUEIRA et al., 2015).

O monitoramento do processo é de essencial para garantir seu adequado andamento, sendo necessário acompanhar os fatores que influenciam a compostagem, tais como: temperatura, aeração, umidade, microrganismos, dimensões das partículas e relação C:N. Os processos de compostagem são caracterizados em função de suas características, podendo ser classificadas da seguinte maneira: quanto à biologia (aeróbio, anaeróbio ou misto), quanto à temperatura (criofílico, mesofílico e termofílico), quanto ao ambiente (aberto e fechado) e quanto ao processamento (estático/natural e dinâmico/acelerado).

Um composto maturado apresenta as seguintes características: granulometria $(0,1-2,0 \mathrm{~mm})$, temperatura (de 3 a $5^{\circ} \mathrm{C}$ acima da temperatura ambiente), umidade $(<35 \%)$, densidade $\left(150-350 \mathrm{~kg} / \mathrm{m}^{3}\right)$, odor (terra mofada e bastante tolerável), pH $(7,6$ - 8,0) e coloração cinza escuro/negra (LELIS et al., 2011; PEREIRA NETO, 2011; KIEHL, 2004; MASSUKADO, 2008; MATOS, 2014). A compostagem em grande escala exige investimentos significativos e espaços físicos adequados, normalmente realizados no âmbito rural, entretanto em pequena escala e microescala é possível sua realização em ambientes urbanos, não exigindo maiores investimentos e grandes áreas (PEREIRA NETO, 2013).

O desenvolvimento da compostagem no Brasil ainda é escasso, não sendo amplamente difundida. Historicamente a compostagem no Brasil, não representou grande sucesso, pois muitas experiências foram mal sucedidas, por falta de planejamento e conhecimento tecnológico e ausência de sistemas de coleta seletiva, o que determinou em uma baixa aceitação da compostagem por parte dos gestores públicos (SIQUEIRA et al., 2015).

Segundo o Instituto Brasileiro de Geografia e Estatística (IBGE, 2010), em 2008 existiam 211 unidades de compostagem no Brasil, representado por apenas 14 unidades federativas. Atualmente no estado de São Paulo, somente registram-se regulamentadas (licenciadas) 6 unidades de compostagem, a grande maioria foi 
fechada, devido a problemas ambientais e incômodos a vizinhança relacionada a odores (CETESB, 2016). Foram identificadas 115 experiências de compostagem no estado de São Paulo, entre usinas de triagem, compostagem, outras compostagens comunitárias e pátios urbano de compostagem (SIQUEIRA et al., 2015). Neste trabalho apresenta-se uma avaliação do processo de compostagem em microescala mostrando sua viabilidade, por meio do monitoramento do processo em pilhas de resíduos orgânicos alimentares e de jardinagem e análise dos compostos produzidos.

\section{MATERIAIS E MÉTODOS}

\section{Local da pesquisa}

A pesquisa foi desenvolvida na Unidade Universitária José de Filippi da Universidade Federal de São Paulo - Unifesp, Campus Diadema, que se localiza no bairro Eldorado no município de Diadema/SP. O material orgânico utilizado foi composto pelos resíduos sólidos orgânicos produzidos no preparo das refeições do restaurante universitário, sendo este formado basicamente por: sobras de legumes, verduras e frutas (cascas, talos e folhas). Foram utilizados também resíduos provenientes da jardinagem da Unidade Universitária, como: material de podas, folhagens e sobras de corte de grama. A Tabela 1 apresenta a composição básica do material utilizado na compostagem.

Tabela 1: Composição quali-quantitativa das pilhas de compostagem.

\begin{tabular}{|c|l|l|l|}
\hline Pilhas & Quantidade & Composição & Material \\
\hline 1 & $9,5 \mathrm{~kg}$ & Folhas verdes, casca de ovo, cenoura, tomate, cebola e mamão inteiro. & 0 \\
\hline 2 & $9,6 \mathrm{~kg}$ & Tomate, cebola, cenoura, folhas verdes, beterraba e talos de brócolis. & \\
\hline 3 & $9,0 \mathrm{~kg}$ & $\begin{array}{l}\text { Casca de ovo, berinjela, folhas roxas e verdes, cebola, tomate, beterraba e talos de } \\
\text { brócolis. }\end{array}$ & 9 \\
\hline
\end{tabular}

\section{Montagem das pilhas}

Optou-se pela utilização do método de compostagem em pilhas (pequenas quantidades). O material orgânico proveniente do restaurante universitário foi misturado com os resíduos orgânicos da jardinagem para formar as pilhas. A proporção da mistura foi de $70 \%$ (resíduos da jardinagem) e $30 \%$ (resíduos do restaurante). As pilhas apresentaram formato triangular, deixando os resíduos mais próximos (concentrando a população de microrganismo) para favorecer o aumento da temperatura durante o processo de compostagem. Foram implantadas três pilhas iguais, dispostas lado a lado, com a seguinte configuração e dimensionamento: geometria aproximadamente triangular e medidas com cerca de $50 \mathrm{~cm}$ de altura e $75 \mathrm{~cm}$ de base. 


\section{Controle e monitoramento das pilhas}

As pilhas foram monitoradas, conforme se visualiza na figura 1 , periodicamente, mais especificamente semanalmente, por meio dos seguintes parâmetros principais: quantidade de material (pesado através de uma mini balança portátil digital gancho para pesca marca Weiheng com capacidade de pesagem de $40 \mathrm{~kg}$ ), temperatura (medida pelo menos três vezes por semana, com o auxílio de um termômetro laser digital (marca Benetech), com medições realizadas no topo e no interior das pilhas, antes do reviramento dos resíduos para que a temperatura não fosse modificada), altura da pilha (medidas quinzenalmente utilizando uma fita métrica, as pilhas foram medidas anteriormente ao seu revolvimento e após essa prática, estas foram ajustadas conforme a altura mensurada, umidade (controlada semanalmente), recomenda-se esse monitoramento diariamente (pelo menos no início do processo).

O parâmetro foi controlado fazendo o teste da 'mão', que consiste basicamente em retirar uma amostra do material no interior da pilha e verificar a umidade, se estivesse muito seco era acrescentada água e muito úmido, adicionava-se material seco basicamente resíduo de jardinagem), frequência de revolvimento (realizado quinzenalmente, contudo, para melhor observação, também seria importante o revolvimento diário pelo menos na primeira semana, utilizando uma pá de mão e um rastelo de jardinagem) e tempo de compostagem.

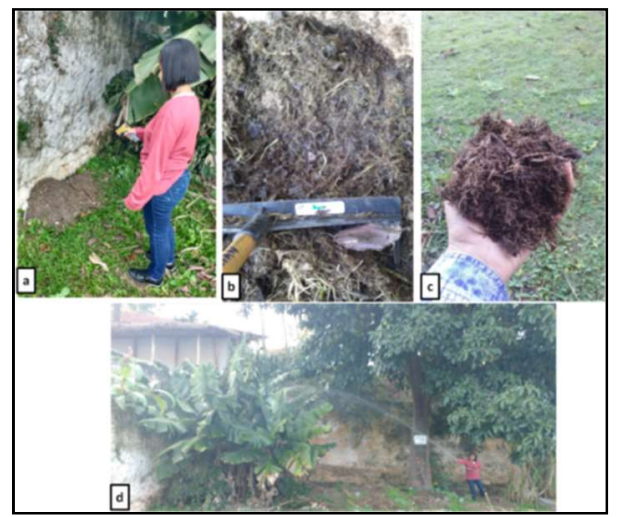

Figura 1: Monitoramento da pilha de compostagem. A: medição da temperatura; b: revolvimento (aeração); c: controle da umidade (teste da 'mão'); e d: umectação da pilha.

\section{Análise da qualidade do composto}

Os procedimentos analíticos das amostras da compostagem foram baseados no Manual de Métodos Analíticos Oficiais para Fertilizantes e Corretivos - MAPA (2014) do Ministério da Agricultura, Pecuária e Abastecimento. Com exceção, dos parâmetros: nitrogênio total que foi analisado pelo método descrito no Manual de Métodos de Análise de Solo da Embrapa (EMBRAPA, 1997) e a matéria orgânica total que foi analisada pelo método descrito por Benaci (2010).

Após 90 dias foram coletadas 3 amostras ( 1 amostra em cada pilha) do material da compostagem e enviados para análise no laboratório de solo da ESALQ - Escola Superior de Agricultura 'Luiz de Queiroz' da USP (Universidade de São Paulo). Antes do envio ao laboratório, as amostras foram preparadas seguindo os seguintes procedimentos: coleta das amostras nas pilhas (utilizando uma pá de jardinagem), armazenamento das amostras em sacos plásticos preto de lixo, transporte das amostras até o Laboratório de Geologia 
Ambiental e Ciência do Solo - Unifesp, Campus Diadema, as amostras foram peneiradas e pesadas utilizando, respectivamente uma peneira e uma balança de laboratório, as amostras foram separadas em alíquotas de 400g e enviadas para análise (figura 2).

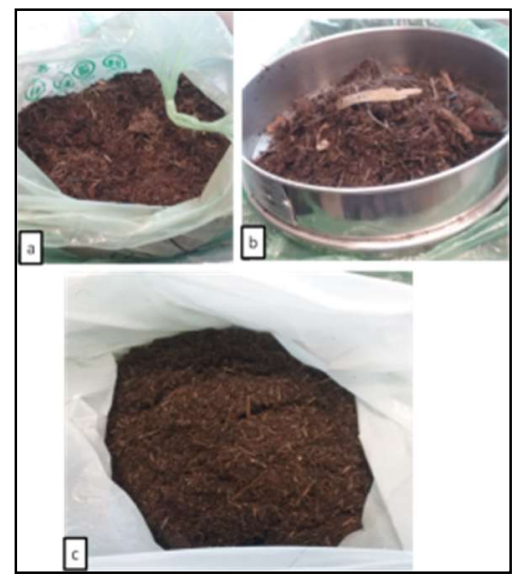

Figura 2: Preparação da amostra para análise laboratorial. A: amostra coletada e armazenada; b - peneiramento da amostra; e c: amostra pronta para envio ao laboratório de análise.

\section{RESULTADOS E DISCUSSÃO}

O período de monitoramento foi de abril a julho de 2016, em torno de 90 dias. As temperaturas médias no interior das pilhas foram de $18,0^{\circ} \mathrm{C}$ (pilha 1 ), $18,2^{\circ} \mathrm{C}$ (pilha 2 ) e $17,9^{\circ} \mathrm{C}$ (pilha 3 ). A temperatura média do ambiente foi de $17,0^{\circ} \mathrm{C}$. As temperaturas no interior das pilhas ficaram mais elevadas, devido à dinâmica do processo de compostagem. As maiores temperaturas ocorrem nos primeiros dias do processo de compostagem, devido à ação dos microrganismos mesófilos que é mais efetiva neste período.

Após esta fase, se inicia a etapa termófila, que apresenta temperaturas mais baixas (BIDONE, 2001; REIS, 2005; BRITO, 2008; INÁCIO et al., 2009). Na literatura, as temperaturas mencionadas das fases da compostagem variam de 45 a $65^{\circ} \mathrm{C}$, porém as pilhas monitoradas atingiram um pico de temperatura de $30,0^{\circ} \mathrm{C}$, valor bem abaixo do recomendado, entretanto mesmo com temperaturas mais baixas não acarretou prejuízos para o processo de compostagem, que efetivamente ocorreu normalmente, culminando com a estabilização da matéria orgânica e, portanto geração do composto.

Tabela 2: Resultado da análise de macro e micronutrientes do composto.

\begin{tabular}{|c|c|c|c|c|}
\hline $\begin{array}{c}\text { Parâmetros } \\
\text { (base seca a 65 }{ }^{\circ} \text { C) }\end{array}$ & Pilha 1 & Pilha 2 & Pilha 3 & $\begin{array}{c}\text { Referência } \\
\text { (padrão de qualidade recomendado) }\end{array}$ \\
\hline Fósforo & $3,10 \%$ & $3,41 \%$ & $2,55 \%$ & $>1,5 \%$ \\
\hline Potássio & $3,46 \%$ & $3,70 \%$ & $2,82 \%$ & $>1,5 \%$ \\
\hline Cálcio & $3,55 \%$ & $3,82 \%$ & $3,43 \%$ & $>3,0 \%$ \\
\hline Nitrogênio & $4,50 \%$ & $6,45 \%$ & $6,33 \%$ & $3,55 \%$ \\
\hline Magnésio & $0,49 \%$ & $0,46 \%$ & $0,34 \%$ & $0,33 \%$ \\
\hline Enxofre & $0,36 \%$ & $0,43 \%$ & $0,34 \%$ & $0,90 \%$ \\
\hline Cobre & $92 \mathrm{mg} / \mathrm{kg}$ & $111 \mathrm{mg} / \mathrm{kg}$ & $80 \mathrm{mg} / \mathrm{kg}$ & $739 \mathrm{mg} / \mathrm{kg}$ \\
\hline Manganês & $622 \mathrm{mg} / \mathrm{kg}$ & $565 \mathrm{mg} / \mathrm{kg}$ & $412 \mathrm{mg} / \mathrm{kg}$ & $267 \mathrm{mg} / \mathrm{kg}$ \\
\hline Zinco & $346 \mathrm{mg} / \mathrm{kg}$ & $454 \mathrm{mg} / \mathrm{kg}$ & $354 \mathrm{mg} / \mathrm{kg}$ & - \\
\hline Ferro & $946 \mathrm{mg} / \mathrm{kg}$ & $856 \mathrm{mg} / \mathrm{kg}$ & $792 \mathrm{mg} / \mathrm{kg}$ & - \\
\hline Boro & $22 \mathrm{mg} / \mathrm{kg}$ & $20 \mathrm{mg} / \mathrm{kg}$ & $20 \mathrm{mg} / \mathrm{kg}$ & - \\
\hline Sódio & $6914 \mathrm{mg} / \mathrm{kg}$ & $7400 \mathrm{mg} / \mathrm{kg}$ & $6451 \mathrm{mg} / \mathrm{kg}$ & \\
\hline
\end{tabular}

Fonte: Inácio et al. (2009); TEIXEIRA et al. (2004). 
Os valores obtidos para fósforo, potássio, cálcio e nitrogênio das pilhas estão todos acima do padrão recomendado, portanto, é um composto com elevada qualidade. A pilha 1 é rica em fósforo, potássio, cálcio, nitrogênio, magnésio, zinco, ferro e sódio. A pilha 2 é rica em fósforo, potássio, cálcio, nitrogênio, magnésio, zinco, ferro e sódio. Já a pilha 3 é rica em fósforo, potássio, cálcio, nitrogênio, magnésio, zinco e sódio.

O fósforo, potássio e nitrogênio são muito empregados em plantios de mudas para que as plantas cresçam satisfatoriamente, geralmente são usados na forma sintética (industrializada) como adubo NPK (nitrogênio-fósforo-potássio). O nitrogênio é um macronutriente importantíssimo no processo de compostagem, além da relação com o carbono, que deve estar equilibrada para garantir o sucesso de formação do composto, este elemento se encontra normalmente de forma orgânica, e devido às atividades microbianas, uma pequena porcentagem se mineraliza para amônia (SÁNCHEZ-MONEDERO et al. 2000).

Já o fósforo está presente em todas as estruturas da planta, auxiliando em seu crescimento, floração e formação de sementes e, tem como papel converter a energia solar em química, favorecendo o processo de fotossíntese. Outro macronutriente de grande importância para as plantas é o cálcio, que tem como função auxiliar no transporte de nutrientes e na síntese de enzimas (LOPES, 1998).

O cobre, ferro, manganês e zinco, são considerados micronutrientes e apresentam importância nutricional e crescimento das plantas. Normalmente, em culturas agrícolas esses elementos são adequados pela aplicação de adubação corretiva no solo. O boro apresenta função de sintetizar enzimas, transportar glicose e atua na divisão celular. O cobre é essencial na fotossíntese, produção de sementes e como elemento constituinte das paredes celulares. O ferro é importante na fotossíntese e em algumas funções associadas às enzimas.

Já o manganês é importante para a produção das estruturas celulares que farão a fotossíntese (cloroplastos). O zinco auxilia na síntese de algumas enzimas e de material genético (RAIJ, 1983; GIRACCA e NUNES, 2016). O magnésio está presente na composição da clorofila e ainda auxilia na síntese de enzimas (RAIJ, 1983). Já o enxofre está presente na composição celular dos cloroplastos. Muito raramente todos os nutrientes estão disponíveis no solo, portanto, é comum a aplicação de fertilizantes químicos. Os micronutrientes, apesar de aplicados em menor quantidade, são tão importantes quanto os macronutrientes, eles ajudam tanto no crescimento como no desenvolvimento das culturas agrícolas (CARVALHO, 2016).

A tabela 3 apresenta outros parâmetros da análise das amostras das pilhas de compostagem. Os valores obtidos nas amostras das pilhas de compostagem estão adequados considerando a Instrução Normativa (IN) N.o 25/2009 do Ministério da Agricultura, Pecuária e Abastecimento (MAPA, 2009). O pH das amostras das pilhas variou de 6,9 a 7,1 (referência IN=6,0). Este parâmetro é importante, pois afeta as raízes das plantas inibindo seu pleno desenvolvimento em faixas de elevada acidez ou alcalinidade (SANTOS, 2007).

A umidade, segundo a IN N.ㅇ 25/2009, apresenta como valor de referência o máximo de 50\%, nas amostras das pilhas analisadas, a umidade variou de 36,20 a $41,38 \%$ apresentando-se dentro do padrão. Para a matéria orgânica total o valor de referência é de no mínimo 40\%, nas amostras esses valores variaram de 75,90 a 84,03\%, indicando que o composto analisado apresenta excelente qualidade. A matéria orgânica é 
fundamental para a formação e fertilidade do solo, pois regula o fluxo de água, fornece nutrientes às plantas e promove a dinâmica das atividades biológicas, já que é fonte de energia e carbono, de forma que dá continuidade ao processo (INÁCIO et al., 2009).

A relação carbono/nitrogênio na compostagem é muito importante, pois possibilita compreender o grau de maturação do composto (SANTOS, 2007). Os valores encontrados nas amostras das pilhas de compostagem variaram de 6 a 9 (referência IN=18, valor máximo), mostrando que o composto efetivamente apresenta um grau de maturação adequada. O carbono orgânico tem valor de referência pela IN de no mínimo $15 \%$, sendo que os valores obtidos variaram entre 33,99 a 44,37\%, portanto, mostra que há uma boa quantidade deste nutriente, o que representa uma indicação de matéria orgânica.

Uma explicação para a obtenção de temperaturas mais baixas nas pilhas monitoradas é em relação ao fato de que estas foram formadas com uma quantidade pequena de material, diferentemente do que normalmente ocorre em sistemas de compostagem maiores. De maneira geral, as pilhas apresentaram uma redução de cerca de $50 \%$ do volume inicial. 0 tempo de compostagem foi de aproximadamente 3 meses, o que é bastante satisfatório. As tabelas 2 e 3 apresentam os resultados obtidos nas amostras do composto que foram encaminhadas para análise química.

Os resultados obtidos com as análises das amostras das pilhas de compostagem indicam que o composto apresenta boa qualidade em termos de fertilidade e efetivamente pode ser utilizado como substrato para enriquecimento do solo. Pois, os nutrientes que foram utilizados durante a decomposição, permanecem dentro da massa microbiana e nas substâncias húmicas. A compostagem tende a reter a grande parte dos nutrientes na forma de substância orgânica estável (INÁCIO et al., 2009).

Tabela 3: Resultados da análise das amostras das pilhas de compostagem.

\begin{tabular}{|c|c|c|c|c|c|}
\hline Parâmetros & Base & Pilha 1 & Pilha 2 & Pilha 3 & Referência* \\
\hline $\mathrm{pH}$ & Úmida & 7,1 & 7,0 & 6,9 & $\begin{array}{c}6,0 \\
\text { (valor mínimo) }\end{array}$ \\
\hline $\begin{array}{c}\text { Densidade } \\
\text { (Resíduo Orgânico) }\end{array}$ & Úmida & $0,44 \mathrm{~g} / \mathrm{cm}^{3}$ & $0,46 \mathrm{~g} / \mathrm{cm}^{3}$ & $0,44 \mathrm{~g} / \mathrm{cm}^{3}$ & - \\
\hline $\begin{array}{c}\text { Umidade } \\
\left.\text { (Resíduo orgânico: } 65^{\circ} \mathrm{C}\right)\end{array}$ & Úmida & $36,69 \%$ & $41,38 \%$ & $36,20 \%$ & $\begin{array}{c}50 \% \\
\text { (valor máximo) }\end{array}$ \\
\hline $\begin{array}{c}\text { Umidade } \\
\left.\text { (Resíduo orgânico: } 110^{\circ} \mathrm{C}\right)\end{array}$ & Úmida & $2,10 \%$ & $1,85 \%$ & $1,30 \%$ & - \\
\hline Matéria Orgânica Total & $\begin{array}{c}\text { Seca } \\
\left(65^{\circ} \mathrm{C}\right)\end{array}$ & $75,90 \%$ & $77,06 \%$ & $84,03 \%$ & $\begin{array}{c}40 \% \\
\text { (valor mínimo) }\end{array}$ \\
\hline Carbono orgânico & $\begin{array}{c}\text { Seca } \\
\left(65^{\circ} \mathrm{C}\right)\end{array}$ & $39,99 \%$ & $40,26 \%$ & $44,37 \%$ & $\begin{array}{c}15 \% \\
\text { (valor mínimo) }\end{array}$ \\
\hline Resíduo Mineral Total & $\begin{array}{c}\text { Seca } \\
\left(65^{\circ} \mathrm{C}\right)\end{array}$ & $20,80 \%$ & $19,79 \%$ & $13,93 \%$ & - \\
\hline Resíduo Mineral & $\begin{array}{c}\text { Seca } \\
\left(65^{\circ} \mathrm{C}\right)\end{array}$ & $16,24 \%$ & $17,25 \%$ & $13,15 \%$ & - \\
\hline Resíduo Mineral Insolúvel & $\begin{array}{c}\text { Seca } \\
\left(65^{\circ} \mathrm{C}\right)\end{array}$ & $4,56 \%$ & $2,54 \%$ & $0,78 \%$ & - \\
\hline Relação C/N & \begin{tabular}{c} 
Úmida \\
\hline
\end{tabular} & 9 & 6 & 7 & 18 \\
\hline
\end{tabular}

Fonte: MAPA (2009).

\section{CONCLUSÕES}

A análise química do composto mostrou resultados muito satisfatórios. A partir dos resultados, observou-se que diversos valores de referência foram ultrapassados, mostrando que a compostagem em 
microescala apresenta alto potencial de uso. Fundamentalmente, atividades descentralizadas em relação à micro compostagem podem ser eficientes na tarefa de desviar resíduos da disposição final e têm a vantagem de mobilizar e sensibilizar pessoas, podendo ser utilizado como fator de valorização de resíduos sólidos orgânicos e, principalmente o desenvolvimento de programas de educação ambiental. Por fim, a compostagem em microescala mostrou-se viável do ponto de vista técnico, apresentando um composto com boa qualidade e fertilidade, sendo possível sua utilização como condicionador orgânico do solo.

\section{REFERÊNCIAS}

BARREIRA, L. P.; PHILIPPI JUNIOR, A.; RODRIGUES, M. S.. Usinas de compostagem do Estado de São Paulo: qualidade dos compostos e processos de produção. Engenharia Sanitária Ambiental, Rio de Janeiro, v.11, n.4, p.385-393, 2006.

BARROS, R. T. V.. Elementos de Gestão de Resíduos Sólidos. Belo Horizonte: Tessitura, 2012.

BENACI, V.. Avaliação de métodos de análise para carbono orgânico em amostras de interesse agronômico. Campinas: Instituto Agronômico, 2010.

BIDONE, F. R. A.. Resíduos sólidos provenientes de coletas especiais: eliminação e valorização. Rio de Janeiro: ABES, 2001.

BRITO, M. J. C.. Processo de Compostagem de Resíduos Urbanos em Pequena Escala e Potencial de Utilização do Composto como Substrato. Dissertação (Mestrado em Engenharia de Processo) - Universidade Tiradentes, Aracaju, 2008.

CARLESSO, W. M.; RIBEIRO, R.; HOEHNE, L.. Tratamento de resíduos a partir de compostagem e vermicompostagem. Revista Destaques Acadêmicos, Lajeado, v.3, n.4, p.105-110, 2011.

CARVALHO, M. C. S.. Micronutrientes. Brasília: Agência Embrapa de Informações Tecnológicas, 2016.

CETESB. Companhia Ambiental do Estado de São Paulo. Inventário Estadual de Resíduos Sólidos Urbanos - 2015 São Paulo: CETESB, 2016.

EMBRAPA. Empresa Brasileira de Pesquisa Agropecuária. Manual de métodos de análise de solo. Rio de Janeiro: EMBRAPA, 1997.

GIRACCA, E. M. N.; NUNES, J. L. S.. Fertilizantes: micronutrientes. Manaus: Agrolink, 2016.

GOMES, L. P.; KOHL, C. A.; SOUZA, C. L. L.; REMPEL, N.; MIRANDA, L. A. S.; MORAES, C. A. M.. Avaliação ambiental de aterros sanitários de resíduos sólidos urbanos precedidos ou não por unidades de compostagem. Engenharia Sanitária Ambiental, v.20, n.3, p.449-462, 2015.

IBGE. Instituto Brasileiro de Geografia e Estatística. Pesquisa Nacional de Saneamento Básico. Rio de Janeiro: IGBE, 2010.
INÁCIO, C. T.; MILLER, P. R. M.. Compostagem: ciência e prática para a gestão de resíduos orgânicos. Rio de Janeiro: Embrapa Solos, 2009.

KIEHL, E. J.. Manual de Compostagem: maturação e qualidade do composto. 4 ed. Piracicaba: EJK, 2004.

LELIS, M. P. N.; PEREIRA NETO, J. T.. Usinas de reciclagem de lixo: porque não funcionam?. In: CONGRESSO BRASILEIRO DE ENGENHARIA SANITÁRIA E AMBIENTAL, 21. Anais. João Pessoa: 2001.

LIMA, L. M. Q.. Lixo: tratamento e biorremediação. São Paulo: Hemus, 2004.

LOPES, A. S.. Manual internacional de Fertilidade do Solo. 2 ed. Piracicaba: ABPPF, 1998.

LOUREIRO, D. C.; AQUINO, A. M.; ZONTA, E.; LIMA, E.. Compostagem e vermicompostagem de resíduos domiciliares com esterco bovino para a produção de insumo orgânico. Pesquisa Agropecuária Brasileira, v.42, n.7, p.1043-1048, 2007.

MAPA. Ministério da Agricultura, Pecuária e Abastecimento. Instrução Normativa n.25/2009. Normas sobre as especificações e as garantias, as tolerâncias, o registro, a embalagem e a rotulagem dos fertilizantes orgânicos simples, mistos, compostos, organominerais e biofertilizantes destinados à agricultura. Brasília: MAPA, 2009.

MAPA. Ministério da Agricultura, Pecuária e Abastecimento. Manual de métodos analíticos oficiais para fertilizantes minerais, orgânicos, organominerais e corretivos. Brasília: MAPA, 2014.

MASSUKADO, L. M.. Desenvolvimento do processo de compostagem em unidade descentralizada e proposta de software livre para o gerenciamento municipal dos resíduos sólidos domiciliares. Tese (Doutorado em Engenharia) - Universidade de São Paulo, São Carlos, 2008.

MATOS, A. T.. Tratamento e aproveitamento agrícola de resíduos sólidos. Viçosa: EDUFV, 2014.

PEREIRA NETO, J. T.. Gerenciamento do Lixo Urbano: aspectos técnicos e operacionais. Viçosa: EDUFV, 2013.

PEREIRA NETO, J. T.. Manual de Compostagem: processo de baixo custo. 3 ed. Viçosa: EDUFV, 2011. 
RAIJ, B. V.. Avaliação da fertilidade do solo. Piracicaba: Instituto de Potassa \& Fosfato, 1983.

REIS, M. F. P.. Avaliação do processo de compostagem de resíduos sólidos urbanos. Tese (Doutorado em Engenharia) Universidade Federal do Rio Grande do Sul, Porto Alegre, 2005.

SÁNCHEZ-MONEDERO, M. A.; ROIG, A.; PAREDES, C.; BERNAL, M. P.. Nitrogen transformation during organic waste composting by the Rutgers system and its effects on $\mathrm{pH}, \mathrm{EC}$ and maturity of the composting mixtures. Bioresources Technology, v.78, p.301-308, 2001.
SANTOS, J. L. D.. Caracterização físico-química e biológica em diferentes laboratórios de produtos obtidos a partir da compostagem de resíduos orgânicos biodegradáveis. Tese (Doutorado em Zoologia e Antropologia) - Faculdade de Ciências da Universidade do Porto, Porto, 2007.

SIQUEIRA, T. M. O.; ASSAD, M. L. R. C. L.. Compostagem de resíduos sólidos urbanos no estado de São Paulo (Brasil). Ambiente \& Sociedade, v.18, n.4, p.243-264, 2015.

TEIXEIRA, L. B.; GERMANO, V. L. C.; OLIVEIRA, R. F.; FURLAN, J. J.. Processo de compostagem a partir de lixo orgânico urbano em leira estática com ventilação natural. Belém: EMBRAPA Amazônia Oriental, 2004. 